\title{
Construção de projeto de vida de jovens: desafios para atuação profissional no contexto da socioeducação
}

\section{Construction of life project for youth: challenges for professional performance in the context of socio-education}

\author{
Maria de Fatima Pereira Alberto (orcid.org/0000-0003-2515-9571)' \\ Manuella Castelo Branco Pessoa (orcid.org/0000-0003-3523-8708)2 \\ Cibele Soares da Silva Costa (orcid.org/0000-0002-7004-2818)³ \\ Erlayne Beatriz Félix de Lima Silva (orcid.org/0000-0002-3380-2881) ${ }^{4}$ \\ Tâmara Ramalho de Sousa Amorim (orcid.org/0000-0002-6126-5200) ${ }^{5}$
}

\begin{abstract}
Resumo
Este artigo tem como objetivo analisar as ferramentas utilizadas pelos profissionais que atuam na aplicação, execução e monitoramento do sistema socioeducativo para auxiliar na elaboração do projeto de vida dos jovens. A amostra foi composta por profissionais da execução e da gestão das medidas de meio aberto e meio fechado e do Sistema de Garantia de Direitos, sendo realizados três grupos de discussão, analisados por meio do MAXQDA. Foram apresentadas três categorias: o que temos, o que necessitamos e o que podemos fazer. Os dados alertaram para dificuldades enfrentadas por todos esses profissionais em sua atuação em relação à construção do projeto de vida, os quais indicaram a necessidade de melhoria das condições de trabalho e de capacitações e formações que promovam maior compreensão acerca das ferramentas a serem utilizadas nos espaços de atuação e que contribuam para a prática pedagógica necessária para a atuação.
\end{abstract}

Palavras-chave: Socioeducação. Projeto de vida. Juventude. Atuação profissional.

\footnotetext{
Abstract

This article aims to analyze the tools used by the professionals who work in the application, execution and monitoring of the socio-educational system to assist in the elaboration of life project for youth. The sample was

${ }^{1}$ Universidade Federal da Paraíba, João Pessoa, Brasil. E-mail: jfalberto@uol.com.br.

2 Universidade Estadual da Paraíba, Campina Grande, Brasil. E-mail: manucastelobranco2@gmail.com.

3 Universidade Federal da Paraíba, João Pessoa, Brasil. E-mail: cibele_sscosta@yahoo.com.br.

4 Universidade Federal da Paraíba, João Pessoa, Brasil. E-mail: erlayne.beatriz@gmail.com.

5 Universidade Federal da Paraíba, João Pessoa, Brasil. E-mail: tamara.rsa@gmail.com.
} 
composed of professionals of the execution and management of measures open and closed environment and the Rights Guarantee System, with tree discussion groups being carried out, analyzed through MAXQDA. Three categories were presented: what we have, what we need and what we can do. The data warned of difficulties faced by all these professionals in their work in relation to the construction of the life project, which indicated the need to improve working conditions and training that promote greater understanding of the tools to be used in the performance spaces and that contribute to the pedagogical practice necessary for the performance.

Keywords: Socio-education. Life project. Youth. Professional performance.

No Brasil, na luta pelos direitos da infância e adolescência, destaca-se a Constituição Federal (CF, 1988), que traz em seu art. 227 o dever do Estado, da sociedade e da família em assegurar o cuidado e a proteção aos direitos das crianças, adolescentes e jovens brasileiros.

É dever da família, da sociedade e do Estado assegurar à criança, ao adolescente e ao jovem, com absoluta prioridade, o direito à vida, à saúde, à alimentação, à educação, ao lazer, à profissionalização, à cultura, à dignidade, ao respeito, à liberdade e à convivência familiar e comunitária, além de colocá-los a salvo de toda forma de negligência, discriminação, exploração, violência, crueldade e opressão (CF, 1988, art. 227).

Tendo como norteadora a Constituição de 1988, institui-se o Estatuto da Criança e do Adolescente (ECA), promulgado pela Lei n. 8.069, de 1990, como um dos acontecimentos fundamentais, pois, a partir deste, inicia-se a doutrina da proteção integral. Isso significa que, a partir de então, crianças e adolescentes devem ser considerados como sujeitos de direitos, ficando a garantia destes sob a responsabilidade do Estado, da família e da sociedade. Por determinação do ECA, o jovem que comete um ato infracional é responsabilizado com o cumprimento de medidas socioeducativas (MSE), tanto em meio aberto como em meio fechado, cujo objetivo consiste na tentativa de reinserção social e do fortalecimento dos vínculos afetivos, familiares e comunitários, respeitando a condição 
peculiar de desenvolvimento.

Com o intuito de regulamentar a execução das medidas socioeducativas, foi criado o Sistema Nacional de Atendimento Socioeducativo (Sinase), por meio da Resolução $\mathrm{n}$. 119/2006 (Conselho Nacional dos Direitos da Criança e do Adolescente, 2006), e da Lei n. 12.594/2012, cujo objetivo é ordenar e sistematizar o atendimento destinado aos adolescentes autores de atos infracionais. O atendimento socioeducativo comporta uma dupla dimensão: sancionatória e pedagógica. O caráter sancionatório corresponde à sanção aplicada ao jovem, e visa à responsabilização diante do ato infracional e desaprovação da conduta infracional, que pode ser executada por meio das MSE de restrição e privação de liberdade (Costa, 2015).

A dimensão pedagógica da socioeducação tem por objetivo realizar ações diretas e encaminhamentos para a rede de proteção, de modo a promover a inserção nas políticas sociais de promoção do desenvolvimento (inserção escolar, programas profissionalizantes, de cultura, lazer e esportes, acesso aos atendimentos na rede de saúde e socioassistencial), e assegurar seus direitos à saúde, à educação, ao sistema de justiça, à assistência social, à proteção e à segurança (Campos \& Cavalcante, 2014). A finalidade do atendimento socioeducativo é oportunizar ao jovem a construção do seu projeto de vida, a partir do que Ihe é ofertado (Pereira \& Mathias Junior, 2016).

$\mathrm{Na}$ promoção e proteção desses direitos, os profissionais da socioeducação são atores essenciais, estando incluídos os profissionais do sistema de justiça responsáveis pela aplicação da MSE de acordo com o ato infracional praticado e das condições do jovem em cumpri-la, e também por avaliar a extinção ou progressão das MSE; os profissionais que compõem o quadro das unidades de execução da MSE de meio aberto e fechado, tais como gestores, equipe técnica, agentes socioeducativos, professores e orientadores educacionais, responsáveis pelo cumprimento da dimensão pedagógica da MSE e dos eixos estabelecidos no PIA (Pereira \& Mathias Junior, 2016).

Além destes, o Sinase define o acompanhamento dos profissionais que compõem o Sistema de Garantia de Direitos (SGD): conselheiros tutelares, profissionais da saúde, educação e assistência social, responsáveis por garantir os direitos sociais dos jovens em 
cumprimento de MSE (Pereira \& Mathias Junior, 2016). Os conselhos tutelares, especificamente, assumem um papel de monitoramento, no sentido da efetivação dos direitos dos jovens em cumprimento de medida socioeducativa, aplicando as medidas de proteção previstas no ECA, se for verificada ameaça ou violação desses direitos (Lemos, Magalhães \& Silva, 2011).

Logo, fica garantido e especificado por lei que o processo de desenvolvimento do jovem deve ser priorizado, devendo ser possibilitadas diversas inserções nas políticas públicas que promovam e que auxiliem esse processo. Entretanto, como apontam Souza, Paiva e Oliveira (2013), esse olhar para o desenvolvimento acaba sendo negligenciado pelas políticas voltadas para o jovem, revelando que estar determinado em lei não é sinônimo de ser efetivado. Logo, como aponta Garcia (2013), se faz necessário criar ações e atividades que equilibrem as reações juvenis com o mundo em que vivem, possibilitando uma base para o surgimento da ação criadora e potencializando o desenvolvimento. Nesse sentido, o que é necessário para auxiliar esse desenvolvimento? Neste artigo, tomando como base a teoria histórico-cultural vigotskiana, entendendo que o desenvolvimento se dá por meio de um processo de apropriação de signos culturais, que não ocorre de maneira natural e linear, mas de forma dialética (Martins, 2016; Tuleski, 2008), ou seja, por meio da superação por incorporação dos aspectos biológicos pelos sociais (Anjos \& Duarte, 2016).

Essa apropriação dos signos culturais é um processo mediado que se dá pela interação do ser mais desenvolvido com o ser em desenvolvimento, na qual o primeiro transmite ao segundo a cultura construída historicamente (Anjos \& Duarte, 2016). Para que isso ocorra, é necessário haver condições sociais objetivas que o favoreçam, assim, o desenvolvimento resulta tanto das condições sociais de vida quanto da natureza e da qualidade das mediações interpostas entre ambos (Marsiglia \& Saccomani, 2016; Martins, 2016). Como aponta García (2013), é necessário enriquecer o meio, estimulando o jovem no sentido de orientar e transformar seus interesses.

Nessa perspectiva, é preciso considerar que para cada período de desenvolvimento há uma força motriz que o impulsiona, e no caso do desenvolvimento juvenil se trata da formação dos interesses, entre eles, a formulação de projetos de vida (Vigotski, 
1931/2006). Nesse sentido, o projeto de vida corresponde a uma questão central do desenvolvimento dos jovens, no qual a atividade dominante se dá por intermédio da comunicação íntima/pessoal e atividade de estudo/profissionalização (Anjos \& Duarte, 2016; Leal \& Mascagna, 2016).

De acordo com Maia e Mancebo (2010), o projeto de vida se constitui como a capacidade de elaboração e planejamento, por parte do jovem, das metas, objetivos e interesses da sua vida, considerando-se as condições concretas de realização. É a elaboração de um plano capaz de impulsionar o desenvolvimento do jovem, construído a partir das condições materiais de vida e suas relações sociais, caracterizando-se por sua dinamicidade, tendo em vista que se modifica a partir das conquistas e entraves que se apresentam na trajetória. Nessa perspectiva, faz-se necessário que a cultura promova condições sociais objetivas que favoreçam a criação de tais projetos, pois é a partir da disponibilização dessas condições que o jovem refletirá sobre suas expectativas, embora a sociedade tenda a revestir esse processo pela aparência da escolha (Leal \& Mascagna, 2016).

O projeto de vida não ocorre de forma isolada, associa-se à qualidade das relações sociais existentes, sendo a relação com a geração adulta um dos fatores determinantes para impulsionar o desenvolvimento dos jovens e transmitir as experiências socialmente produzidas (Trancoso \& Oliveira, 2014). Nessa relação com os adultos, os jovens passam a formar os pontos de vista gerais sobre a vida, sobre o futuro, sobre as relações interpessoais, sendo que uma das formas de se preparar para esse futuro se dá por meio da inserção em instituições que forneçam a formação escolar/profissional (Anjos \& Duarte, 2016; Leal \& Mascagna, 2016), as quais desempenham papel fundamental na trajetória de vida, podendo oportunizar e potencializar o desenvolvimento.

No caso dos jovens a quem são atribuídas a autoria de atos infracionais, as instituições que executam as medidas socioeducativas são responsáveis por favorecer a construção do projeto de vida, por meio da oferta de um conjunto de ações e articulações entre as políticas sociais, de modo a garantir o desenvolvimento da autonomia e das habilidades relacionais, cognitivas e produtivas (Lei n. 12.594, 2012). Na operacionalização dessa atividade, o Plano Individual de Atendimento (PIA) constitui o instrumento que 
possibilita a estruturação de um plano para a execução da medida socioeducativa, além de possibilitar o acompanhamento da evolução pessoal e social do jovem e de sua família, por meio do estabelecimento de metas e objetivos, e conduzir as ações dos profissionais responsáveis pela socioeducação (Teixeira, 2014). O PIA, de acordo com o Sinase (Lei n. 12.594, 2012), deve ser construído pela equipe técnica da unidade de MSE, com a participação ativa do jovem e de sua família, sendo esse instrumento submetido à avaliação do judiciário, no que se refere à avaliação do cumprimento da medida socioeducativa.

A corresponsabilidade da família, no que diz respeito à sua participação na ação socioeducativa, juntamente com a sociedade e o Estado, foi preconizada pelo ECA e reiterada pelo Sinase, o qual estabelece, entre suas diretrizes pedagógicas, a participação ativa da família e da comunidade (Sinase, 2006). Como afirmam Medeiros e Paiva (2015), no Sinase parte-se do pressuposto de que tudo o que está relacionado ao adolescente e sua formação relaciona-se também, extensivamente, a sua família.

Nesse sentido, o Sinase (2006) dispõe que as instituições que executam medidas socioeducativas devem proporcionar o desenvolvimento de atividades como: integração entre adolescentes e seus familiares; atendimento familiar; participação da família na construção do PIA; visitas domiciliares; e encaminhamento das famílias a programas públicos de assistência social e de geração de renda. Entretanto, é necessário que o Estado possibilite que essas atividades sejam realizadas, proporcionando condições de trabalho e condições estruturais para que os profissionais possam promovê-las, pondo em prática a participação da família na ação socioeducativa e auxiliando na construção do projeto de vida do jovem.

Sehn, Porta e Siqueira (2015), ao investigar a possibilidade da construção de projeto de vida a partir das perspectivas dos jovens em cumprimento da MSE de semiliberdade, identificaram que o oferecimento de cursos profissionalizantes, as articulações com instituições de emprego e o retorno à escola serviram como elementos de reconstrução da trajetória de vida, auxiliaram na criação de projetos de vida e no afastamento dos atos infracionais. Tais elementos, identificados por esses autores, correspondem às atividades principais da construção do projeto de vida no período da juventude, destacando-se as 
necessidades de maior investimento por parte das instituições executoras de MSE e de articulação dos profissionais da socioeducação para a efetivação da garantia de direitos dos jovens.

Pereira e Barone (2015) discutem que, para auxiliar os jovens no cumprimento da medida socioeducativa, os profissionais que atuam no campo da socioeducação necessitam da formação continuada para a execução dessa atividade, tendo em vista as especificidades do atendimento e os inúmeros entraves apresentados à política de socioeducação e à efetivação do Sinase, o que exige a presença de um suporte teórico-técnico permanente nas instituições (Macedo \& Dimenstein, 2012). Como forma de reconhecimento dos desafios para a consolidação do trabalho nas instituições do Sistema de Garantia de Direitos, o Conselho Nacional dos Direitos da Criança e do Adolescente (Conanda, 2006), por meio da Resolução n. 112/2006, instituiu os parâmetros para a formação continuada dos operadores do SGD, afirmando-a como necessária e estratégica para a concretização dos direitos de crianças e adolescentes e fortalecimento das instituições (Sinase, 2006).

Também se faz importante, como assinala Barreto (2011), a criação de espaços voltados à escuta e cuidado dos profissionais que trabalham nas políticas sociais, seja por meio de momentos de supervisão, reflexão e formação continuada, seja por meio do suporte dos demais profissionais, tendo em vista a complexidade das questões que fazem parte do cotidiano desses profissionais, como a violência, seja ela estrutural, institucional, seja interpessoal, e as desigualdades econômicas, sociais e políticas.

Dessa maneira, entende-se a necessidade de que as questões acerca do desenvolvimento juvenil sejam discutidas com os profissionais que atuam com os jovens que cumprem medidas socioeducativas. Tal demanda decorre da determinação da legislação brasileira e é justificada também teoricamente, uma vez que esses profissionais são responsáveis por operacionalizar, diretamente, o atendimento socioeducativo e por promover ações que favoreçam a construção do projeto de vida desses jovens.

Desse modo, este artigo tem como objetivo analisar as ferramentas utilizadas pelos profissionais que atuam na aplicação, execução e monitoramento do sistema socioeducativo para auxiliar na elaboração do projeto de vida dos jovens. Constata-se que, apesar das 
determinações e ferramentas proporcionadas a partir dos avanços legais dos últimos anos, o funcionamento do sistema socioeducativo continua ocorrendo de forma precária, inviabilizando a realização de atividades de caráter pedagógico (Medeiros \& Paiva, 2015). Diante disso, parte-se do pressuposto de que os profissionais apresentam dificuldades em trabalhar temas como projeto de vida com os jovens que cumprem medidas socioeducativas, estando suas práticas mais atreladas a ações burocráticas e às necessidades de melhoria das suas condições de trabalho.

\section{Método}

\section{Participantes}

A amostra foi composta por profissionais dos Centros de Referências Especializado da Assistência Social (Creas); de Unidades de Meio Fechado; da gestão das medidas de meio aberto e meio fechado; do sistema de justiça; e conselho tutelar no estado da Paraíba. Explicou-se que a participação não era obrigatória e que seria guardado sigilo dos nomes e setores específicos aos quais os participantes estavam vinculados.

\section{Técnicas e instrumento}

Foram realizados, concomitantemente, três grupos de discussão com os participantes, divididos de acordo com as instituições às quais estavam vinculados. O grupo de discussão, como método de pesquisa, constitui-se como importante ferramenta que auxilia a reconstrução dos contextos sociais e dos modelos que orientam as ações dos sujeitos. Como afirma Godoi (2015), essa técnica tem como foco recuperar a participação ativa do sujeito na pesquisa, outorgando-Ihe a liberdade para expressar sua opinião sobre o sentido de suas ações relacionadas à vida cotidiana. Dessa forma, a técnica possibilitou acessar o cotidiano dos profissionais participantes, principalmente no que diz respeito a suas práticas com os jovens que estão em cumprimento de medidas socioeducativas, a 
partir dos discursos produzidos coletivamente, justificando assim suas ações dentro da realidade.

Isso posto, iniciou-se a discussão a partir da seguinte pergunta geradora: diante da realidade vivenciada por vocês nas instituições, como auxiliar na construção dos projetos de vida dos jovens? De forma a apoiar a discussão, fez-se um protocolo para os participantes, contendo três questões norteadoras: o que temos? O que necessitamos? O que podemos fazer? Tais perguntas foram escolhidas com o objetivo de identificar quais ferramentas são utilizadas pelos profissionais do sistema socioeducativo, considerando a experiência legítima dos sujeitos, suas necessidades e possibilidades de atuação diante da realidade do cotidiano de atuação (Gadotti, 2012). A partir do diálogo entre pesquisadores e profissionais, buscou-se refletir sobre as ferramentas utilizadas e suscitar o reconhecimento de estratégias de intervenção facilitadoras da construção do projeto de vida dos jovens.

\section{Análise de dados}

A análise dos grupos foi feita com o auxílio do MAXQDA, que é um software de apoio a investigações qualitativas, a partir do desenvolvimento de códigos para as categorias que emergem dos dados empíricos, podendo ser configurado de acordo com as necessidades do pesquisador (Souza, Costa \& Moreira, 2010). Destarte, a análise seguiu os seguintes passos: a) organização dos dados; b) divisão dos dados em unidades manipuláveis; c) sintetização dos dados; d) busca de padrões nas respostas; e) elaboração dos resultados a partir da análise dos dados.

Com base no protocolo utilizado como instrumento para a discussão da pergunta geradora, as questões propostas foram consideradas como as três grandes categorias de análise: 1. O que temos, com os seguintes códigos: demanda, infraestrutura, ferramentas para atuação e atuação. 2. O que necessitamos, com os códigos: ferramentas para atuação, efetivação da legislação, capacitação profissional e centralidade no profissional. 3. O que é possível fazer, com os códigos: ações para os profissionais, ações para as famílias e ações 
para os jovens. O detalhamento pode ser visto na Figura 1.

Figura 1. Categorias e subcategorias

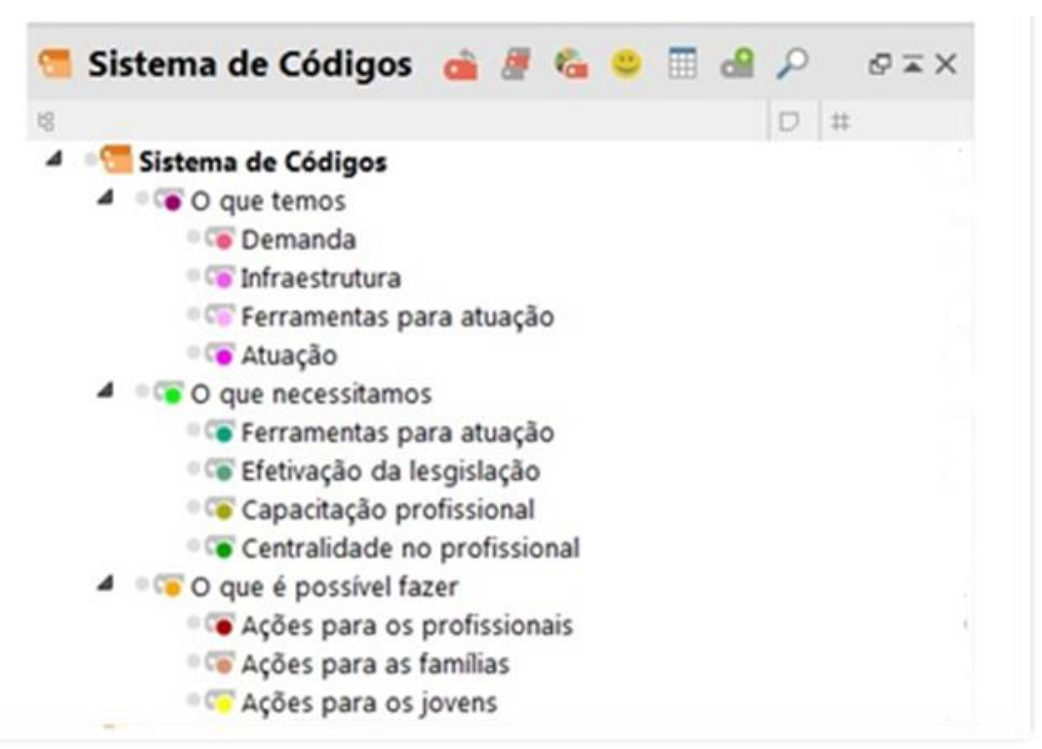

Fonte: Elaborada pelas autoras.

\section{Resultados e discussão}

Os resultados serão apresentados de forma conjunta, ou seja, considerando o conjunto das respostas dos grupos de profissionais da aplicação, execução e monitoramento do sistema socioeducativo. De forma geral, a partir das questões norteadoras, percebeu-se que os participantes responderam dizendo o que tinham, mas também refletindo sobre o que não tinham e o que necessitavam para realizar o trabalho. Apesar de a pergunta geradora ter sido relacionada à maneira de auxiliar na construção dos projetos de vida dos jovens, as respostas dos profissionais foram, em sua maior parte, centralizadas em sua própria prática profissional, em suas dificuldades e necessidades, como se estivessem chamando a atenção para a necessidade de construir primeiro seu próprio projeto de vida para que possam ter condições de auxiliar os jovens. O detalhamento dos resultados, com as categorias e códigos, pode ser visto a seguir. Quando questionados acerca do que os profissionais do sistema socioeducativo dispõem em suas respectivas instituições, houve um predomínio de respostas relacionadas à atuação 
profissional, sendo mencionada pela maioria dos participantes dos grupos (40\%), seguida por questões relacionadas à infraestrutura (25\%), como pode ser visto na Figura 2.

Figura 2. O que temos?

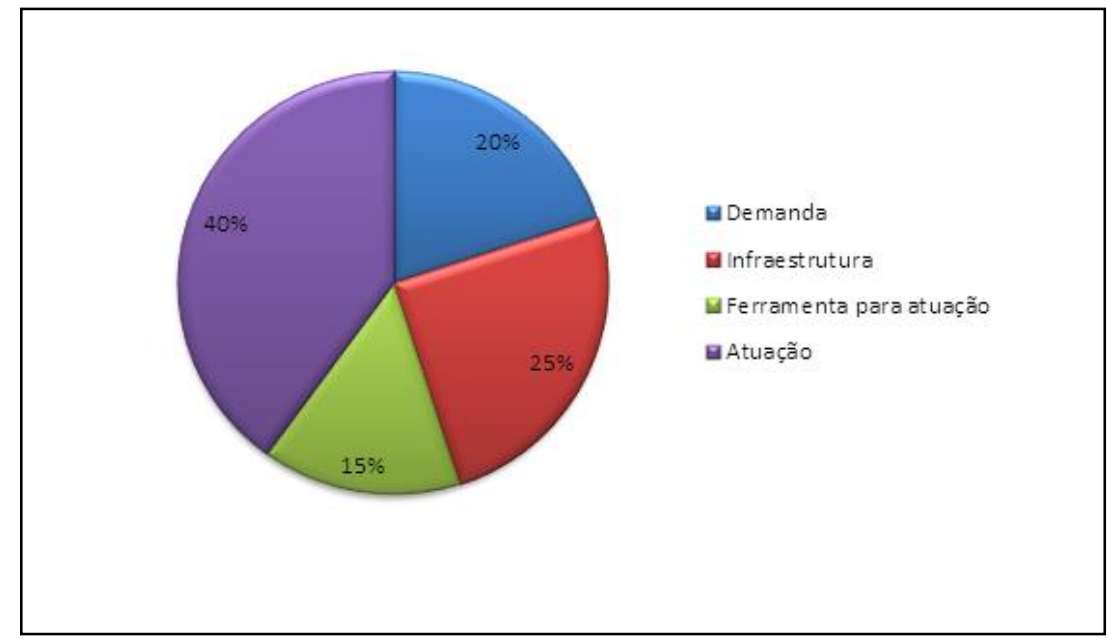

Fonte: Elaborada pelas autoras.

No código atuação, emergiram respostas como: profissionais capacitados, o fato de as instituições terem equipes multiprofissionais, articulação com a rede, mas também foi possível observar sentimento de frustração por parte de alguns deles devido às dificuldades e limitações da atuação no cotidiano institucional. A infraestrutura emergiu nas falas dos profissionais relacionada à estrutura física do local de trabalho, que foi considerada por eles como satisfatória, mas também foram feitas referências à situação de superlotação das unidades de privação de liberdade e à omissão do Estado em relação a essa situação. As demandas elencadas pelos profissionais estavam relacionadas, principalmente, à atuação com os jovens e suas famílias, revelando a demanda em excesso e o que chamaram de “jovens sem perspectiva”. E, por último, em relação às ferramentas de atuação, emergiram em suas falas referências aos instrumentos metodológicos utilizados por eles e também às leis que embasam suas atuações.

Observou-se que os profissionais apresentaram um olhar crítico em relação a suas atuações e às condições ofertadas para a realização destas, tendo em vista que eles 
reconhecem os elementos necessários para atuação, tais como a existência de profissionais capacitados e de instrumentos metodológicos legais, bem como as limitações que se colocam no seu cotidiano de trabalho. E, a partir disso, afirmam que buscam pautar suas atuações nos parâmetros legais que regulamentam o atendimento aos jovens em cumprimento de medidas socioeducativas, tais como o Sinase e o ECA (Sehn, Porta \& Siqueira, 2015).

Entretanto, os profissionais enfrentam dificuldades relacionadas às condições concretas para a consolidação de suas práticas profissionais, devido ao excesso de demanda (Pereira \& Barone, 2015), o que, muitas vezes, os impede de planejar junto com os jovens ações que os guiem na construção de seus projetos de vida, os quais acabam sendo oportunizados a partir de relações sociais precarizadas e individualizadas. Essas condições são contrárias ao que seria necessário, conforme aponta a literatura (Trancoso \& Oliveira, 2014; Maia \& Mancebo, 2010), no que se refere à importância do compartilhamento de experiências entre adultos e jovens, para que sejam estabelecidas relações que impulsionem o desenvolvimento desses sujeitos e a construção de seus respectivos projetos de vida.

Quando convidados a refletir sobre o que precisavam para auxiliar na construção dos projetos de vida dos jovens, a maioria das respostas se referia à efetivação da legislação (32\%), em relação à necessidade de aumento do número de profissionais atuando, de agilidade dos serviços e organização das estruturas. Também emergiram outras questões, ilustradas na Figura 3. 
Figura 3. O que necessitamos?

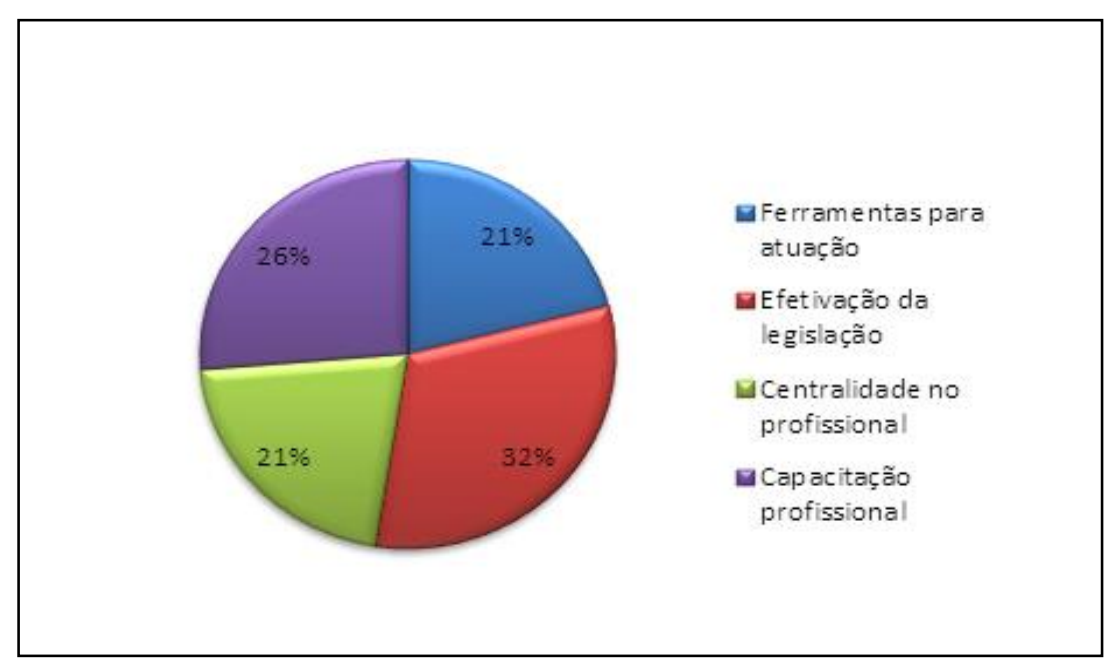

Fonte: Elaborada pelas autoras.

Apesar de alguns participantes considerarem que já têm profissionais capacitados, esse não foi um ponto de vista compartilhado por todos. A capacitação dos profissionais foi outro tema apontado como necessário (26\%); as respostas se referiam à necessidade de investimento na formação dos agentes socioeducativos que trabalham diretamente com os jovens e também uma formação continuada para os demais profissionais que atuam em suas respectivas instituições. Ainda que tenham reconhecido, na categoria "O que temos?", a existência de algumas ferramentas, como instrumentos metodológicos, os profissionais apontaram a necessidade de outras ferramentas para atuação nesse âmbito (21\%), como oferta de materiais e a implementação de novas práticas, a exemplo da justiça restaurativa. Pode-se perceber ainda que alguns dos profissionais sinalizaram para questões particulares, ou seja, centradas neles mesmos (21\%), chamando atenção para a necessidade de construção de seus projetos de vida, como profissionais, de serem ouvidos e estimulados a atuar ali.

Percebe-se que os profissionais identificam a necessidade de efetivação dos parâmetros legais, tais como Sinase e ECA, para execução de seus trabalhos, conforme preconizado nas legislações. Além de reconhecer a importância da atualização das práticas profissionais, por meio da oferta de capacitação profissional continuada, aspecto 
considerado pela literatura como fundamental para os profissionais que trabalham com a execução das medidas socioeducativas e no Sistema de Garantia de Direitos, tendo em vista a complexidade dessa política e da efetivação dos parâmetros legais relativos a ela (Pereira \& Barone, 2015).

Após refletirem sobre o que tinham disponível e o que necessitavam para a atuação, auxiliando na construção dos projetos de vida dos jovens, Ihes foi perguntado, então, o que era possível fazer diante daquele cenário. As respostas se dividiram em: ações para os profissionais $(58,8 \%)$, ações para os jovens $(29,5 \%)$ e ações para as famílias $(11,7 \%)$, como pode ser visto na Figura 4.

Figura 4. O que é possível fazer?

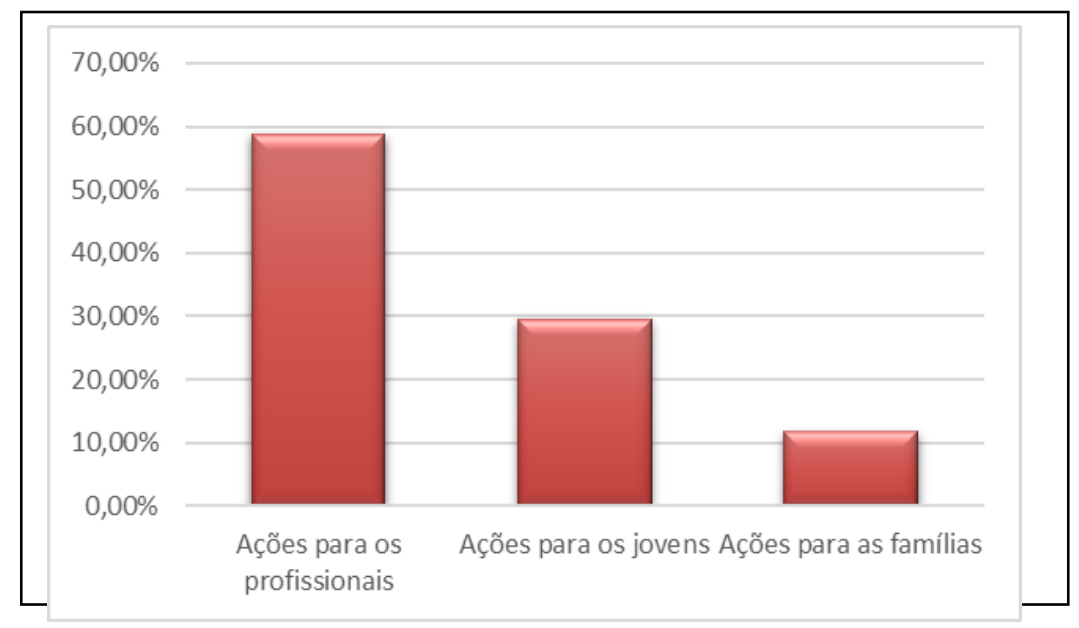

Fonte: Elaborada pelas autoras.

Em geral, os profissionais voltam seus olhares para suas próprias práticas, elencando possibilidades de ações para os profissionais, como: melhoramento da segurança preventiva, investir na intersetorialidade entre as políticas sociais para a implementação do Plano Estadual de Atendimento Socioeducativo, encaminhar/requisitar encaminhamento para a rede. Aparentemente, há um entendimento em relação ao que está regulamentado no Sinase (Lei n. 12.594, 2012): os profissionais expõem em suas falas a possibilidade de sistematizar uma série de ações que estão voltadas para esses jovens - como também 
apontam Campos e Cavalcante (2014) -, porém apresentam respostas generalistas, parecendo apenas repetir o que está prescrito em leis e resoluções. A prática pedagógica, como defendem Pereira e Mathias Junior (2016), emerge como restrita às ações de encaminhamento, contudo, não ficam claras em suas falas informações sobre o direcionamento necessário para ações que oportunizem projetos de vida.

Os profissionais defendem ainda a necessidade de atividades de motivação da equipe e a possibilidade de trabalhar seus projetos de vida, como profissionais, para que possam posteriormente intervir sobre esse tema com os jovens, trazendo crenças que remetem ao "é necessário acreditar sempre e não perder a esperança". Ou seja, chamam a atenção para a necessidade de criar um espaço no qual possam ser escutados e cuidados também, como afirma Barreto (2011). A formação continuada pode ser uma possibilidade de espaço nesse sentido (Pereira \& Barone, 2015), podendo funcionar de maneira a atender às demandas profissionais que Ihes chegam nesses espaços de atuação. Além disso, a precarização das condições de trabalho para os profissionais das políticas sociais, representada nas falas sobre falta de infraestrutura e das dificuldades existentes na rede de serviços, não dá suporte aos encaminhamentos e compromete os fluxos de atendimento (Macedo \& Dimenstein, 2012). Porém, chama atenção aqui, mais uma vez, que os profissionais não operacionalizam em suas falas possibilidades voltadas aos jovens, no sentido de ferramentas para a construção de projetos de vida. Eles apresentam suas necessidades como algo que precisa ser atendido primeiro para que, assim, possam atender às dos jovens com os quais atuam. Tudo isso faz com que o processo de desenvolvimento desse jovem sofra as consequências, pois, diante das necessidades trazidas pelos profissionais, muitas devido à precarização de suas condições de trabalho, os jovens acabam não sendo postos como prioritários, o que torna ainda mais problemático o processo de formação de concepção de mundo por parte do jovem, como salientam Anjos e Duarte (2016).

Quando se referiram às ações para os jovens, eles elencaram as atividades de: orientar, aconselhar, advertir, acompanhar e realizar acolhimento. Já as possíveis ações com as famílias, ficaram no âmbito da orientação e do fortalecimento de vínculos, não 
abrangendo todas as atividades de participação da família, como está posto no Sinase (2006), constituindo atividades que soam mais como assistencialismo do que como uma ação para a autonomia. Para além disso, tais atividades acontecem de maneira individualizada, enquanto, em concordância com Anjos e Duarte (2016), se faz necessária uma intervenção pedagógica pautada no coletivo, e não apenas no indivíduo isoladamente.

Questiona-se o que de fato vem sendo apropriado por esses jovens em cumprimento de medidas socioeducativas (Martins, 2016; Tuleski, 2008), o que vem, de fato, sendo possibilitado? Se entendemos e defendemos que os profissionais atuam como referenciais que contribuem para que os jovens aprendam a se desenvolver e se relacionar socialmente (Leal \& Mascagna, 2016), ficam diversos hiatos nas atuações que apontam para a falta de condições sociais objetivas que favoreçam o jovem em cumprimento de medidas. A qualidade das mediações interpostas entre ambos (Marsiglia \& Saccomani, 2016) produzirá e determinará a subjetividade desses sujeitos, devendo ser garantido um espaço privilegiado que favoreça o desenvolvimento. Isso está disposto na lei, porém, o que parece é que esta se encontra distante de sua efetivação.

A formulação de projetos de vida dos jovens - questão central do seu desenvolvimento (Vigotski, 1931/2006) - não é citada pelos profissionais em suas falas. Logo, a criação de espaços que promovam condições sociais objetivas que favoreçam a criação de tais projetos parece ser secundarizada (Leal \& Mascagna, 2016). A medida socioeducativa que, em seu caráter pedagógico, deveria promover a elaboração e planejamento de metas, objetivos e interesses por parte dos jovens, acaba falhando, verificando que apenas o caráter sancionatório tem sido aplicado (Costa, 2015), funcionando muito mais como um espaço de pseudodesenvolvimento, como apontam Marsiglia e Saccomani (2016).

Também não foi relatada pelos profissionais a inserção em instituições que forneçam a formação escolar/profissional, determinada pelo Sinase (Lei n. 12.594, 2012), bem como a elaboração do Plano Individual de Atendimento (PIA) pelos profissionais técnicos das unidades de execução da MSE. Curiosamente, estas são postas pela lei como as principais ferramentas possibilitadoras da estruturação e execução da medida socioeducativa. Dessa 
forma, os profissionais que compõem o Sistema de Garantia de Direitos aparentam apresentar pouco conhecimento sobre as ferramentas que podem ser utilizadas para auxiliar na elaboração do projeto de vida desses jovens. Suas práticas se mostram mais voltadas para si, para suas necessidades profissionais, que não são atendidas devido às precárias condições de trabalho, do que para os jovens que cumprem medidas socioeducativas, não priorizando as necessidades desses sujeitos.

Destaca-se a efetiva utilização do PIA como ferramenta que irá auxiliar a construção dos projetos de vida dos jovens. A potencialidade desse instrumento se dá desde a maneira pela qual este é construído, inicialmente com as escutas, conhecimento sobre a história do jovem, mapeamento das instituições e redes de garantia de direitos, estudos de caso, interesses e objetivos.

Além disso, por agrupar informações sobre a previsão, o registro e gestão das atividades, tanto em relação ao momento de cumprimento da MSE como a previsão de atividades a serem realizadas após o término da medida, tal instrumento funciona como um guia de ação para os profissionais e para os jovens e familiares refletirem sobre as ações realizadas, nas diversas áreas da vida do jovem. Possibilita ainda elencar os objetivos que ainda necessitam ser alcançados, de modo que sua participação na construção do projeto de vida seja real e não se encerre em um plano idealizado ou predeterminado, além de possibilitar a integração das informações acerca das interlocuções com as demais políticas sociais (Teixeira, 2014). Os desafios postos para sua utilização partem de extrapolar o aspecto burocrático que esse documento pode assumir, compreendendo-se a flexibilidade e o caráter pedagógico que pode adquirir.

Neste artigo apresentaram-se as diversas dificuldades por parte dos profissionais do sistema socioeducativo em trabalhar temas como projeto de vida com os jovens que cumprem medidas socioeducativas, não tendo sido identificadas ferramentas para essa finalidade, apesar dos dispositivos determinados nos marcos legais que subsidiam o Sinase. Foi possível perceber que essas dificuldades não estão relacionadas à falta de vontade individual dos profissionais, mas às frágeis condições de trabalho em que eles se encontram nos diversos espaços de aplicação, execução e monitoramento das MSE - corroborando o 
encontrado por Medeiros e Paiva (2015) -, as quais são denunciadas por eles quando centram suas falas nos entraves que encontram e no excesso de burocratização das atividades, chamando atenção para a necessidade que têm de serem escutados nas suas reivindicações e de terem espaços de cuidados.

Associada à questão das condições de trabalho, está a necessidade apontada pelos profissionais da implementação da formação continuada, que forneça subsídios para a atuação de acordo com o Sinase e de modo a favorecer espaços de discussão, aprendizagem e trocas de experiências relacionadas à construção do projeto de vida dos jovens. Assim, longe de culpabilizar esses profissionais, o que recairia na individualização de questões que são estruturais, cumpre-se o papel social de esclarecer, pensar possibilidades de trabalho e trazer à luz situações e dificuldades enfrentadas nesse contexto, com o intuito de contribuir para um avanço mais significativo na efetivação da socioeducação.

\section{Considerações finais}

Diante do objetivo deste estudo de analisar as ferramentas utilizadas pelos profissionais que atuam na aplicação, execução e monitoramento do sistema socioeducativo para auxiliar na elaboração do projeto de vida dos jovens, pode-se compreender que os profissionais reconheceram a existência de ferramentas e instrumentos específicos da atuação no âmbito da socioeducação, sinalizados a partir do Sinase. Entretanto, eles não vêm conseguindo utilizar essas ferramentas, na prática, nas instituições, revelando que o objetivo das MSE de oferecer aos jovens, por meio da garantia dos direitos sociais, a possibilidade para a construção de projetos de vida, desvinculados da prática de atos infracionais, está longe de se efetivar.

Confirma-se, a partir das falas dos profissionais nos grupos de discussão, que tais dificuldades estão presentes nos diferentes espaços institucionais, desde a aplicação, durante a execução das medidas socioeducativas, o que, por sua vez, se traduz no comprometimento do atendimento ao jovem em cumprimento de MSE, uma vez que este deve se pautar pela integração das diversas políticas sociais e, por meio destas, assegurar 
os direitos dos jovens. Os profissionais apontaram ainda a necessidade de capacitações e formações continuadas que proporcionem maior compreensão acerca das ferramentas a serem utilizadas nas unidades de atuação para auxiliar os jovens na construção de projetos de vida.

Os resultados desta pesquisa podem contribuir para a formação e atuação no sistema socioeducativo, na medida em que evidenciaram as dificuldades enfrentadas pelos profissionais no cotidiano da atuação mediante a construção do projeto de vida, destacando-se a necessidade de ações que forneçam a esses atores maior conhecimento acerca da utilização dos instrumentais relacionados à socioeducação e à prática pedagógica fundamental para embasar essa atuação. Nesse sentido, as capacitações continuadas no âmbito do sistema socioeducativo são indispensáveis para a consolidação do Sistema de Garantia de Direitos, por fornecer os conteúdos teóricos e práticos para a atuação dos profissionais. Tais capacitações podem funcionar como espaços de interlocução entre os serviços, nos quais os profissionais podem trocar experiências, discutir as dificuldades e compartilhar as estratégias de enfrentamento que utilizam diante das especificidades do atendimento no sistema socioeducativo. Além disso, a disponibilização das capacitações pode funcionar como espaços de escuta para os profissionais, de modo a trabalhar os aspectos que repercutem nos profissionais e que concorrem para a não construção dos projetos de vida dos jovens.

Convém ressaltar que as considerações provenientes desta pesquisa se referem à realidade do sistema socioeducativo em um estado da região Nordeste, apontando-se a necessidade de pesquisas que analisem as ferramentas utilizadas pelos profissionais em âmbito nacional, considerando a diversidade do território brasileiro e também as determinações do Sistema Nacional de Atendimento Socioeducativo.

\section{Referências}

Anjos, R. E., \& Duarte, N. (2016). A adolescência inicial: comunicação íntima pessoal, atividade de estudo e formação de conceitos. In L. M. Martins, A. A. Abrantes \& M. G. 
D. Facci (Orgs.). Periodização histórico-cultural do desenvolvimento psíquico: do nascimento à velhice (pp. 241-266). Capinas, SP: Autores Associados.

Barreto, A. F. (2011). Sobre a dor e a delícia da atuação psicológica no Suas. Psicologia: Ciência e Profissão, 37(2), 406-419. doi: 10.1590/S1414-98932011000200015.

Campos, H. R., \& Cavalcante, C. P. (2014). O adolescente e o estatuto jurídico: transgressão e lei no Brasil. In I. L. Paiva, C. Souza \& D. B. Rodrigues (Orgs.). Justiça juvenil: teoria e prática no sistema socioeducativo (pp. 33-48). Natal, RN: EDUFRN.

Costa, C. (2015). Dimensões da medida socioeducativa: entre o sancionatório e o pedagógico. Textos \& Contextos, 14(1), 62-73. doi: 10.15448/16779509.2015.1.16858.

Constituição da República Federativa do Brasil de 1988. (1988). Brasília. Recuperado de http://www.planalto.gov.br/ccivil_03/constituicao/constituicao.htm.

Gadotti, M. (2012). Educação popular, Educação social, Educação comunitária: conceitos e práticas diversas, cimentadas por uma causa comum. Revista Diálogos: Pesquisa em Extensão Universitária, 18(1), 10-32.

García, L. D. (2013). Juventud, responsabilidad y compromiso social. Havana, Cuba: Universidad de La Habana.

Godoi, C. K. (2015). Grupo de discussão como prática de pesquisa em estudos organizacionais. Revista de Administração de Empresas, 55(6), 632-644.

Leal, Z. F. R. G., \& Mascagna, G. C. (2016). Adolescência: trabalho, educação e formação omnilateral. In L. M. Martins, A. A. Abrantes \& M. G. D. Facci, (Orgs.). Periodização histórico-cultural do desenvolvimento psíquico - do nascimento à velhice (pp. 221 237). Campinas: Autores Associados.

Lei n. 8.069, de 13 de julho de 1990. (1990). Dispõe sobre o Estatuto da Criança e do 
Adolescente e dá outras providências. Brasília, DF. Recuperado de http://www.planalto.gov.br/ccivil_03/leis/18069.htm.

Lei $n^{\circ} 12.594$, de 18 de janeiro de 2012. (2012). Institui o Sistema Nacional de Atendimento Socioeducativo (Sinase), regulamenta a execução das medidas socioeducativas destinadas a adolescente que pratique ato infracional; e altera as Leis $n^{\circ} \mathrm{s} 8.069$, de 13 de julho de 1990 (Estatuto da Criança e do Adolescente); 7.560, de 19 de dezembro de 1986, 7.998, de 11 de janeiro de 1990, 5.537, de 21 de novembro de 1968, 8.315, de 23 de dezembro de 1991, 8.706, de 14 de setembro de 1993, os Decretos-Leis $\mathrm{n}^{\circ} \mathrm{s}$ 4.048, de 22 de janeiro de 1942, 8.621, de 10 de janeiro de 1946, e a Consolidação das Leis do Trabalho (CLT), aprovada pelo Decreto-Lei $n^{\circ} 5.452$, de $1^{\circ}$ de maio de 1943. Brasília, DF. Recuperado de http://www.planalto.gov.br/ccivil_03/_ato20112014/2012/lei/l12594.htm.

Lemos, D. L., Magalhães, S. S., \& Silva, V. O. (2011). Atribuições do conselho tutelar: proteção integral ou vestígios da doutrina da situação irregular?.Intertem@s Social, 6(6), 1-106.

Macedo, J. P., \& Dimenstein, M. (2012). O trabalho dos psicólogos nas políticas sociais no Brasil. Avances en Psicología Latinoamericana, 30(1), 182-192. Recuperado de http://bit.ly/2FYKOxT.

Maia, A. A. R. M., \& Mancebo, D. (2010). Juventude, trabalho e projetos de vida: ninguém pode ficar parado. Psicologia: Ciência e Profissão, 30(2), 376-389.

Marsiglia, A. C. G., \& Saccomani, M. C. S. (2016). Contribuições da periodização históricocultural do desenvolvimento para o trabalho pedagógico histórico-crítico. In L. M. Martins, A. A. Abrantes, \& M. G. D. Facci (Orgs.). Periodização histórico-cultural do desenvolvimento psíquico: do nascimento à velhice (pp. 241-266). Campinas, SP: Autores Associados.

Martins, L. M. (2016). Psicologia Histórico-Cultural, Pedagogia Histórico-Crítica e 
desenvolvimento humano. In L. M. Martins, A. A. Abrantes \& M. G. D. Facci (Orgs.). Periodização histórico-cultural do desenvolvimento psíquico: do nascimento à velhice (pp. 241-266). Campinas, SP: Autores Associados.

Medeiros, F. C., \& Paiva, I. L. (2015). A convivência familiar no processo socioeducativo de adolescentes em privação de liberdade. Estudos e Pesquisas em Psicologia, 15(2), 568-586. Recuperado de http://bit.ly/2D44ZXO.

Pereira, I., \& Mathias Junior, M. (2016). A educação em direitos humanos dos socioeducadores de adolescentes em conflito com a lei. RIDH, 4(2), 23-42. Recuperado de http://bit.ly/215ml5f.

Pereira, I., \& Barone, R. E. M. (2015). Formação do socioeducador no contexto da socioeducação e as contribuições da educação social. In: P. C. D. Paes, M. F. Adimari \& R. P. Costa (Orgs). Socioeducação e intersetorialidade: formação continuada de socioeducadores (pp: 25-36). Campo Grande, MS: Editora UFMS.

Sehn, S. A., Porta, D. D., \& Siqueira, A. C. (2015). "Tocar a vida para frente": possibilidades de planos para o futuro de adolescentes que cometeram ato infracional. Adolescência \& Saúde, 12(1), 28-34.

Sistema Nacional de Atendimento Socioeducativo - Sinase. (2006). Brasília, DF: Conanda.

Souza, C., Paiva, I. L., \& Oliveira, I. F. (2013). Que política é essa?: Um olhar sobre as políticas de juventude no Brasil. In: I. L. Paiva, M. A. Bezerra, G. S. N. Silva \& P. D. Nascimento (Orgs.). Infância e juventude em contextos de vulnerabilidades $e$ resistências (pp. 77-99). São Paulo, SP: Zagodoni.

Souza, F., Costa, A. P., \& Moreira, A. A. F. G. (2010). WebQDA: software de apoio à análise qualitativa. Comunicação apresentada na $5^{\text {a }}$ Conferência Ibérica de Sistemas e Tecnologias de Informação, CISTI 2010, Santiago de Compostela, Espanha.

Teixeira, M. L. T. (2014). Plano Individual de Atendimento (PIA) - O presente e o futuro do 
adolescente em cumprimento de medida socioeducativa. In I. L. Paiva, C. Souza \& D. B. Rodrigues. Justiça juvenil: teoria e prática no sistema socioeducativo (pp. 101-123). Natal, RN: EDUFRN.

Trancoso, A. E. R., \& Oliveira, A. A. S. (2014). Juventudes: desafios contemporâneos conceituais. Estudos contemporâneos da subjetividade, 4(2), 262-273.

Tuleski, S. C. (2008). Vigotski: a construção de uma Psicologia marxista. Maringá, SP: Eduem.

Vigotski, L. S. (1931/2006). Obras Escogidas (Tomo IV). Madrid, Espanha: Visor.

Recebido em: 17/4/2018 Aprovado em: 20/11/2018 